\title{
A randomized double-blind placebo controlled trial of oral acyclovir in renal allograft recipients
}

\author{
Walter F SChleCh III, MD FACP, FRCPC, NANCy MeAgher, RN, AlLAN D COHEN, MD, FRCPC, \\ PHILIP BELITSKY, MD, FRCSC, AS MACDONALD, MD, FRCSC, JOHN C LEBLANC, MD, FRCPC
}

\begin{abstract}
WF Schlech III, N Meagher, AD Cohen, P Belitsky, AS MacDonald, JC LeBlanc. A randomized double-blind placebo controlled trial of oral acyclovir in renal allograft recipients. Can $J$ Infect Dis 1993;4(2):84-88. Fifty renal transplant patients were randomized to receive either $800 \mathrm{mg}$ acyclovir by mouth four times daily or identical placebo tablets for prophylaxis of herpes simplex infection. Patients were followed weekly to assess reactivation of herpes simplex, varicella zoster virus, Epstein-Barr virus or cytomegalovirus (CMV) infections. The patients received standard immunosuppressive regimens including cyclosporine A. Acyclovir suppressed secretion of herpes simplex virus in treated patients $(\mathrm{P}=0.001)$. Three episodes of mucocutaneous herpes simplex virus occurred in placebo recipients and one in a noncompliant acyclovir recipient. A clinically important difference in graft survival was demonstrated, but because of sample size failed to reach statistical significance $(\mathrm{P}=0.11)$. No reactivation of varicella zoster virus, Epstein-Barr virus or CMV infection was detected in either group. Toxicity was limited to central nervous irritability. The authors conclude that high dose oral acyclovir provides effective prophylaxis for prevention of herpes simplex virus infections in renal transplantation and may be associated with increased graft survival, perhaps from suppression of CMV infection.
\end{abstract}

Key Words: Acyclovir, Herpes viruses, Renal transplant

\section{Un essai randomisé à double insu contrôlé contre placebo de l'acyclovir oral chez des receveurs d'allogreffe}

RÉSUMÉ: Cinquante receveurs d'allograffe rénale ont reçu au hasard soit $800 \mathrm{mg}$ d'acyclovir par voie orale 4 fois par jour, soit des comprimés identiques de placebo, pour la prophylaxie d'une infection à herpèsvirus simplex. Ces patients ont été suivis chaque semaine afin d'évaluer la réactivation des infections dues aux virus herpès simplex, varicelle zooter, Epstein-Barr ou cytomégalovirus (CMV). Les patients ont reçu des traitements immunosupresseurs standard de cyclosporine A. L'acyclovir a supprimé la sécrétion du virus herpès simplex chez les patients traités $(\mathrm{P}=0,001)$. Trois épisodes dûs au virus herpès simplex mucocutané se sont produits dans le groupe placebo, ainsi qu'un autre épisode chez un sujet non observant. Une différence clinique importante dans la survie des greffe s'est manifestée, mais à cause de la taille réduite de l'échantillon, elle n'a pas pu atteindre une signification statistique. Dans aucun des deux groupas, il n'a été détectê de réactivation de l'herpès virus varicellae, du virus Epstein-Barr ou du CMV. La toxicité a été limitée à une irritabilité du système nerveux central. Les auteurs concluant que l'acyclovir à forte dose par voie orale apporte une prophylaxie efficace des infections à herpès virus simplex dans les cas de transplantation rénale, et qu'il peut être associé à une augmentation de survie des greffes, peut-être par suppression de l'infection à CMV.

Victoria General Hospital, Halifax, Nova Scotia

Correspondence and reprints: Dr WF Schlech III, Room 4089 ACC, Victoria General Hospital, 1278 Tower Road, Halifax, Nova Scotia B3H 2 Y9

Received for publication August 26, 1991. Accepted January 21, 1992 
A CYCLOVIR (9- [HYDROXYMETHYL] GUANINE) IS A SYNTHETIC nucleoside analogue with in vitro activity against herpes simplex virus types I and II (HSV I and HSV II), varicella zoster virus (VZV), Epstein-Barr virus (EBV) and human cytomegalovirus (CMV). In both oral and intravenous forms, acyclovir is effective in the treatment of HSV I and II infections in both immunocompromised and normal hosts (1). Acyclovir also has activity against, and has been found to be effective in the treatment of, VZV infections in immunocompromised and competent hosts $(2,3)$, and in vitro and anecdotal human data suggest activity against EBV infections (5).

Herpes viruses cause significant morbidity and mortality in patients undergoing transplantation of kidney, liver, heart and bone marrow. While CMV is the major cause of morbidity and mortality in transplantation, other herpes viruses cause considerable morbidity and occasional mortality in this group. Oral acyclovir has been found to provide effective therapy of mucocutaneous HSV infections in these patients. Because the incidence of herpes virus infection is so high in transplantation, a rationale is present for the use of oral acyclovir prophylactically as well as in treatment.

Previous studies of prophylactic oral acyclovir in renal allograft recipients have used low doses of acyclovir (200 to $400 \mathrm{mg}$ four times daily) for 28 to 42 days following transplantation. Pettersson et al (6) randomized $35 \mathrm{HSV}$ antibody-positive patients to receive 200 $\mathrm{mg}$ oral acyclovir four times daily for 28 days after transplantation. These patients underwent an immunosuppressive regimen using azathioprine and methylprednisolone. Six patients in the placebo group developed typical mucocutaneous HSV, but no clinical infections were noted in the treated group. Two episodes of recrudescent VZV infection occurred. Shedding of HSV in oral secretions increased rapidly following cessation of therapy, although no clinical infections were noted. No effect on CMV excretion or graft rejection was noted.

Seale et al (7) randomized $40 \mathrm{HSV}$ seropositive renal allograft recipients to receive $200 \mathrm{mg}$ acyclovir two to three times daily for 30 days following transplantation. The majority of patients received immunosuppression with azathioprine and corticosteroids as well as antilymphocyte globulin. Thirteen patients also received cyclosporine A and corticosteroids; four patients received azathioprine and corticosteroids alone. In this study, 14 of 21 patients receiving placebo shed HSV in throat washings versus one of 19 acyclovir-treated patients. Following the study, $60 \%$ of placebo recipients and $44 \%$ of acyclovir recipients developed HSV-positive throat washings. The authors suggested that extension of prophylaxis into the second month, when most infections occur, might eliminate this problem.

In a larger study, Stoffel et al (8) randomized 98 patients to receive $200 \mathrm{mg}$ acyclovir four times daily for 42 days. These patients received azathioprine, pred- nisolone and antilymphocyte globulin (ALG), or cyclosporine A and prednisolone therapy. No attempt was made to restrict the study to patients seropositive for HSV infections. No differences were found in HSV shedding in throat washings during the study, although there was a significant decrease in clinical HSV and VZV disease in the treated group. After six weeks of therapy, no subsequent clinical HSV or VZV infections developed.

The authors examined the effectiveness of high dose oral acyclovir in the prevention of human herpes virus infections in renal transplant patients receiving cyclosporine A immunosuppression to determine whether acyclovir suppressive therapy influenced graft survival or morbidity and mortality. High dose therapy was postulated to have an equivalent effect on HSV infection as low dose prophylaxis for HSV but might have a greater effect on VZV, CMV or EBV outcomes and their sequelae.

\section{PATIENTS AND METHODS}

Fifty renal allograft recipients older than 18 years were enrolled in the study over a one-year period. Patients were randomized to receive $800 \mathrm{mg}$ oral acyclovir or identical tablets four times daily for 84 days. Patients were issued drugs every two weeks and tablets were counted to ensure compliance. Over $85 \%$ of prescribed drug was administered. Eligible patients had to have serological evidence for previous HSV infection (complement fixation [CF] titre greater than 1:8), VZV infection (CF titre greater than 1:8) or EBV infection (immunoglobulin G [IgG] titre greater than 1:40, antiEBV nuclear antigen greater than 1:5). Treatment began with $800 \mathrm{mg}$ given by mouth immediately prior to transplantation or when cyclosporine A was begun and was resumed when oral intake restarted after surgery.

Patients were followed weekly post transplantation to assess the development of oral or genital HSV infections, VZV reactivation (typical 'shingles' or disseminated infection), EBV reactivation (typical clinical syndrome plus appearance of IgM antibody to viral capsid antigen and CMV reactivation (typical clinical syndrome plus a positive urine culture for CMV). Hematological profile, urinalysis, and liver and renal function studies were performed weekly for six weeks and then every two weeks for six weeks to determine any potential toxicity of the high dose regimen. Patients continued to be followed for 60 months following transplantation to monitor the potential effects of acyclovir on medium and long term graft survival.

Immunosuppressive regimen: All patients received 5 to $15 \mathrm{mg} /$ day cyclosporine A to keep cyclosporine A levels between 200 and $800 \mathrm{mg} / \mathrm{mL}$. One-half of the patients received 'pulse' prednisone at some point post transplantation for rejection. Three patients received concurrent azathioprine and two received ALG.

Virology: Throat washings were processed and inoculated into monolayers of human foreskin fibroblast cells 
TABLE 1

Patient population

\begin{tabular}{|c|c|c|}
\hline & Acyclovir & Placebo \\
\hline Male:female ratio & $18: 7$ & $13: 12$ \\
\hline Age in years (range) & 37.8 (19 to 58$)$ & 44.5 (18 to 65$)$ \\
\hline \multicolumn{3}{|l|}{ Clinical history of: } \\
\hline Herpes simplex virus & $15(60 \%)$ & $15(60 \%)$ \\
\hline Varicella zoster virus & $17(68 \%)$ & $17(68 \%)$ \\
\hline Epstein-Barr virus & $0(0 \%)$ & $0(0 \%)$ \\
\hline Cytomegalovirus & $0(0 \%)$ & $0(0 \%)$ \\
\hline \multicolumn{3}{|l|}{$\begin{array}{l}\text { Serological evidence of } \\
\text { previous: }\end{array}$} \\
\hline Herpes simplex virus & $20(80 \%)$ & $22(88 \%)$ \\
\hline Varicella zoster virus & $6(24 \%)$ & $2(8 \%)$ \\
\hline Epstein-Barr virus & $24(96 \%)$ & $22(88 \%)$ \\
\hline Cytomegalovirus & $13(52 \%)$ & $12(48 \%)$ \\
\hline Living related donor & $4(16 \%)$ & $1(4 \%)$ \\
\hline 'Pulse' steroids & $11(44 \%)$ & $13(52 \%)$ \\
\hline Azathioprine & $2(8 \%)$ & $1(4 \%)$ \\
\hline Antilymphocyte globulin & $0(0 \%)$ & $2(8 \%)$ \\
\hline \multicolumn{3}{|c|}{$\begin{array}{l}n=25 \text { in both groups. *No significant difference between treatment and } \\
\text { placebo arms were noted for any variable (Fisher's exact test or } x^{2} \text { ) }\end{array}$} \\
\hline \multicolumn{3}{|c|}{$\begin{array}{l}\text { TABLE } 2 \\
\text { Periods of positive herpes simplex virus in throat wash- } \\
\text { ings during the study }\end{array}$} \\
\hline Period of viral shedding & Acyclovir & Placebo \\
\hline None & $23(92 \%)$ & $11(44 \%)$ \\
\hline One & $2(8 \%)$ & $3(12 \%)$ \\
\hline At least two & $0(0 \%)$ & $11(44 \%)$ \\
\hline Total patients & 25 & 25 \\
\hline
\end{tabular}

using standard techniques. Monolayers were observed twice weekly for cytopathological change typical of HSV. Immunofluorescent studies identified $\mathrm{HSV}$ isolates as either HSV I or HSV II.

Assays for herpes simplex and VZV antibody employed standard complement fixation method kits from Biocan Scientific. Antibody to EBV viral capsid antigen was detected using a commercially available kit (Gull Laboratories, Utah). This assay detected IgM and IgG antibody. IgG antibody to EBV nuclear antigen was also determined.

CMV cultures of urine were performed on human embryonic lung cell line and examined weekly for typical cytopathological effect and antibody to CMV was detected using a complement fixation assay.

For the initial 12-week period, placebo and acyclovir groups were compared using the following three outcome measures (calculated for each individual in order to ensure statistical independence).

Periods of shedding: A period of shedding is defined as a throat washing positive for HSV or typical lesions following a negative washing and no lesions at the preceding examination. A positive throat washing at the first examination was counted as a first episode of shedding.
Positive week ratio: The positive week ratio is the ratio of weeks with positive washings or lesions over all the weeks in which examinations were performed.

Mean time to negative washing: For patients with positive throat washings at the start of the trial, this component is defined as the mean time to reversion to negative throat washings. These measures were compared using $\chi^{2}$ and $t$ tests. Survival analysis using Kaplan-Meier estimation was used to compare graft survival between the placebo and acyclovir groups. Survival time was defined as the time from graft insertion to either the first day dialysis was required, date of subsequent graft insertion or date of death.

\section{RESULTS}

Randomization: Twenty-five patients were randomized to receive acyclovir and 25 patients received placebo. Over $85 \%$ of the prescribed drug was administered in both groups. Characteristics of the patient population are noted in Table 1. Acyclovir-treated patients were more often male and somewhat younger, but these differences were not statistically significant. Three patients in the placebo group and two in the acyclovir group were receiving their second renal allografts. Four patients in the acyclovir group and one in the placebo group received an allograft from a living related donor. In addition, no significant differences between groups were found in pretransplant viral serologies or previous clinical evidence of human herpes virus infections. Of interest is the lack of correlation between clinical and serological evidence for previous infection with EBV almost all patients had serological evidence of EBV while no patient gave a history of a typical 'mononucleosis-like' syndrome in the past. A greater correlation was seen for clinical and serological evidence of HSV infection; approximately one-half of the total population had serological evidence of previous CMV infection, a figure consistent with the estimated seroprevalence of CMV in the authors' geographic area.

Immunosuppressive regimens did not differ between the two groups. 'Pulse' steroids were administered to 11 of 25 acyclovir-treated patients versus 13 of 25 placebotreated patients. No differences in the use of azathioprine (two of 25 versus one of 25) or ALG (none of 25 versus two of 25) were noted. All patients receiving these treatments for acute rejection also received 'pulse' steroids.

Development of herpes simplex virus shedding and disease: Table 2 shows the number of patients in the two studies who had none, one or two periods of HSV shedding. Only two episodes of viral shedding occurred in the treatment group compared with 36 in the placebo group during the 12 week follow-up. All the acyclovir group had negative throat washings during the first examination one week after treatment was initiated, compared with $48 \%$ of the placebo group $(\mathrm{P}<0.001$, Fisher's exact test). 
The mean proportion of weeks with positive throat washings was $1.1 \%$ in the acyclovir group compared with $30 \%$ in the placebo group $(\mathrm{P}<0.001)$. The eight patients who were seronegative upon study entry did not shed at any time during the study. Analysis by 'positive week ratio' and 'mean time to negative washings' on therapy showed similar results.

Typical mucocutaneous lesions of HSV developed in three patients in the placebo group and one patient in the treated group ( $\mathrm{P}=0.3$, Fisher's exact test). The latter patient had discontinued the drug for two days in the fifth week of therapy, prior to the onset of a typical lesion of the lower lip. One patient in the placebo group developed a severe perioral HSV infection requiring removal from the study and treatment with intravenous acyclovir.

Graft survival: A trend was noted in patients completing the study for increased graft survival in the acyclovir-treated group. Figure 1 shows Kaplan-Meier graft survival curves for acyclovir and placebo groups. A mean survival time of 150 weeks was noted in the placebo group versus 215 weeks in the acyclovir group ( $\log$ rank=2.56, degree of freedom $[\mathrm{df}]=1, \mathrm{P}=0.11)$. The analysis was repeated for those 42 patients who were seropositive for HSV on trial entry on the assumption that they most likely would benefit from acyclovir; mean survival time was 153 weeks for the placebo group versus 237 weeks for those treated with acyclovir (log rank=4.49, $\mathrm{df}=1, \mathrm{P}=0.034$ ), suggesting that the acyclovir-treated patients were more likely to show graft survival.

Deaths: Two patients in the placebo group died. The first died three weeks after transplantation from an unexpected rupture of an abdominal aortic aneurysm. The second patient had graft failure at eight months and died at nine months because of septic shock from abdominal sepsis. One patient in the acyclovir-treated group died five months after transplantation from cerebrovascular accident and hypocalcemia. This patient had dropped out of the study after two weeks of treatment because of dizziness and sleep disturbance attributed to therapy.

Varicella zoster virus infections: No patient in either group developed clinical evidence of dermatomal VZV reactivation or disseminated infection during the study or follow-up.

Epstein-Barr virus infections: No patient in either group developed clinical or serological evidence of EBV reactivation. No EBV-associated lymphomas have been detected to date in this group of patients.

Cytomegalovirus infections: CMV was not isolated from urine culture obtained in the first two weeks following transplantation in either group. No clinical or serological evidence of primary or reactivated CMV infection was detected in either patient group during the study.

Patient tolerance: No differences were found between acyclovir-treated and placebo groups for hematological,
NUMBER OF GRAFTS SURVIVING

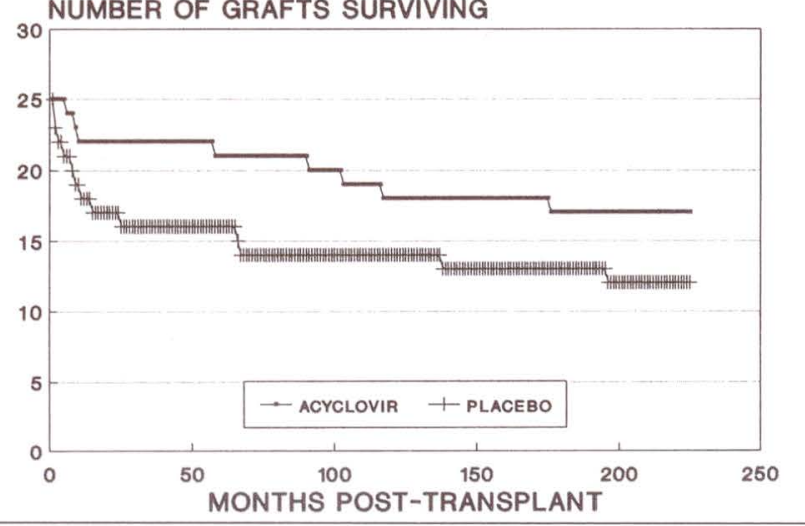

Figure 1) Survival of renal allografts in patients treated with acyclovir or placebo. Mean survival time was greater for acyclovir-treated patients $(\mathrm{P}=0.34)$

\section{TABLE 3}

\section{Reasons for patient withdrawal from study}

\begin{tabular}{lcc}
$\begin{array}{l}\text { Symptoms/signs requiring } \\
\text { discontinuation from study }\end{array}$ & Acyclovir & \begin{tabular}{c} 
Placebo \\
\hline Rejection
\end{tabular} \\
Rash & 2 & 3 \\
Central nervous system symptoms & 5 & 0 \\
Gastrointestinal symptoms & 1 & 3 \\
Severe herpes simplex virus infection & 0 & 1 \\
Sepsis & 0 & 1 \\
Ruptured aortic aneurysm & 0 & 1 \\
Total discontinued & 8 & 1 \\
\hline
\end{tabular}

$n=25$ in both groups; *One patient had skin rash and rejections

hepatic or renal toxicity. The data on toxicity and the reasons for study discontinuation are summarized in Table 3. One dropout in the placebo group was related to severe mucocutaneous perioral HSV infection as noted above and one dropout was due to death in this group from ruptured aneurysm. Five of seven dropouts in the acyclovir-treated group were attributed to central nervous system toxicity. Two patients developed selflimited skin rashes. No skin rashes were noted in the placebo-treated group but there were two central nervous system-related complaints which led to voluntary discontinuation from the study. Three patients in the placebo group and one in the treatment group were dropped from the study because of graft rejection.

\section{DISCUSSION}

This study has demonstrated that high dose oral acyclovir can prevent mucocutaneous HSV infections in renal allograft recipients and has an acceptable toxicity profile. The high dose used appears to suppress shedding of HSV in throat washings to a greater extent than shown in previous low dose studies. Whether this has any clinical benefit is uncertain. Extending prophylaxis beyond six weeks may not be useful because clinical disease and shedding due to HSV appears to occur early in the post transplantation period (two of 
three clinically evident lesions in the placebo group occurred during the first week and one occurred at nine weeks). The only clinical lesion in the treated group occurred at four weeks in a patient who discontinued the study drug for two days. Lower rates of clinical HSV exposure in the presented placebo group than in other studies $(6,7)$ may be due to small study size or decreased severity of the immunosuppressive regimens used.

The four patients who developed clinically evident HSV infections had pretransplant HSV titres of 1:32 or greater. Patients who were seronegative (HSV titres less than 1.8) did not shed HSV or develop clinical lesions. Pretransplant HSV screening can, therefore, select populations at high and low risk of clinical HSV. The authors suggest that patients who are seropositive for HSV should be given prophylactic oral acyclovir for six weeks following transplantation.

This study could not determine the effectiveness of oral acyclovir in preventing VZV or EBV reactivation. There appears to be a lower incidence of VZV reactivation in the current transplant group compared with previously reported studies of this type. However, the small size of this study and differences in immunosuppressive regimens may have prevented the determination of efficacy against HSV despite the higher dosing regimens used in the study for this purpose. The minimal toxicity of high dose oral acyclovir and its effectiveness in managing shingles in immunocompromised patients coupled with its clear effectiveness in preventing HSV infections suggest that prevention of VZV infections may still be a secondary, but important, benefit for a high dose regimen.

The potential effect of acyclovir on graft survival in

ACKNOWLEDGEMENTS: This study was supported by a grant from Burroughs Wellcome. The authors thank the transplant unit, clinic nurses and transplant Coordinator at Victoria General Hospital for invaluable assistance in the study. The authors would also like to thank transplant patients and the physicians in the Maritime provinces for participation in the study, and Daureen Stover and Janice Flynn for preparing the manuscript.

\section{REFERENCES}

1. Dorsky DI, Crumpacker CS. Drugs five years later: Acyclovir. Ann Intern Med 1987;107:859-74.

2. Balfour HH Jr, Bean B, Laskin OL, et al. Acyclovir halts progression of herpes zoster in immunocompromised patients. N Engl J Med 1983:308:1448-53.

3. Bean B, Braun C, Balfour HH Jr. Acyclovir therapy for acute herpes zoster. Lancet 1982;ii: 118-21.

4. Datta AR, Colby BM, Shaw JE, Pagano JS. Acyclovir inhibition of Epstein Barr virus replication. Proc Natl Acad Sci USA. 1980:77:5163-6.

5. Andersson J, Sholdenberg B, Henle W, et al. Acyclovir treatment in infectious mononucleosis: A clinical and virological study. Infection 1987; 15(Suppl):514-20.

6. Pettersson E, Hovi T, Ahonen J, et al. Prophylactic oral this study was intriguing. Herpes simplex suppression was evident but HSV infection is not associated with decreased graft survivals (9).

Acyclovir has some in vitro activity against CMV although its activity is low compared with activity against the other herpes viruses, and higher oral doses might be more beneficial. However, Meyer et al (10) have demonstrated a clinical effect in preventing CMV infections in bone marrow transplant recipients, and primary renal reactivation CMV infections have been associated with decreased renal allograft survival $(11,12)$. It is possible that the trend to improved graft survival seen in this study could have been an indirect manifestation of the activity of high dose oral acyclovir against CMV in the study population. Of the six patients with graft rejection in the placebo group, all had evidence of previous CMV infection or had received a kidney from a CMV-positive seropositive donor. The study size was small, however, and the graft losses occurred early in the study, prior to the usual time of CMV reactivation in this setting. In addition, there were more living related donor transplants in the treatment group which could favorably affect outcome in this group. Balfour et al (13), in a larger study, recently demonstrated that high dose oral acyclovir can suppress CMV infection in renal transplant recipients but has no effect on graft or patient survival. The significant central nervous system toxicity seen in the presented treatment group with high dose therapy suggests that lower dose regimens may be preferable unless a more clear benefit can be demonstrated in a larger study specifically designed to examine graft survival in patients given high dose acyclovir.

acyclovir after renal transplantation. Transplantation 1985:39:279-81.

7. Seale L, Jones CJ, Kathpalias, et al. Prevention of herpes virus infections in renal allograft recipients by low dose oral acyclovir. JAMA 1985;254:3435-8.

8. Stoffel M, Squifflet JP, Pirson Y, Lamy M, Alexandre GPJ. Effectiveness of oral acyclovir prophylaxis in renal transplant recipients. Transplant Proc 1987;2 1:2 190-3.

9. Spencer ES, Fjeldboy O, Mordhoust C-H. Herpes simplex infections in relation to kidney allograft survival. Dan Med Bull 1988:35:499-500.

10. Meyers JD, Reed EC, Shepp DH, et al. Acyclovir for prevention of cytomegalovirus infection and disease after allogenic marrow transplantation. N Engl J Med 1988;318:70-5.

11. Fryd DS, Peterson PK, Ferguson RM, et al. Cytomegalovirus as a risk factor in renal transplantation. Transplantation 1980;30:436-9.

12. Smiley ML, Wlodaver CG, Grossman RA, et al. The role of pretransplant immunity in protection from cytomegalovirus disease following renal transplantation. Transplantation 1985;40:157-61.

13. Balfour HH Jr, Chase BA, Stapleton JT, Simmons RL, Fryd DS. A randomized placebo-controlled trial of acyclovir for the prevention of cytomegalovirus disease in recipients of allografts. N Engl J Med 1989;320:1381-7. 


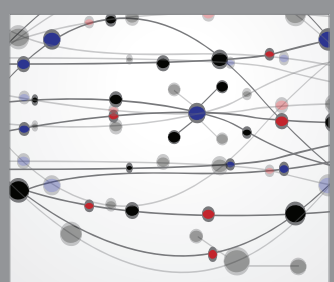

The Scientific World Journal
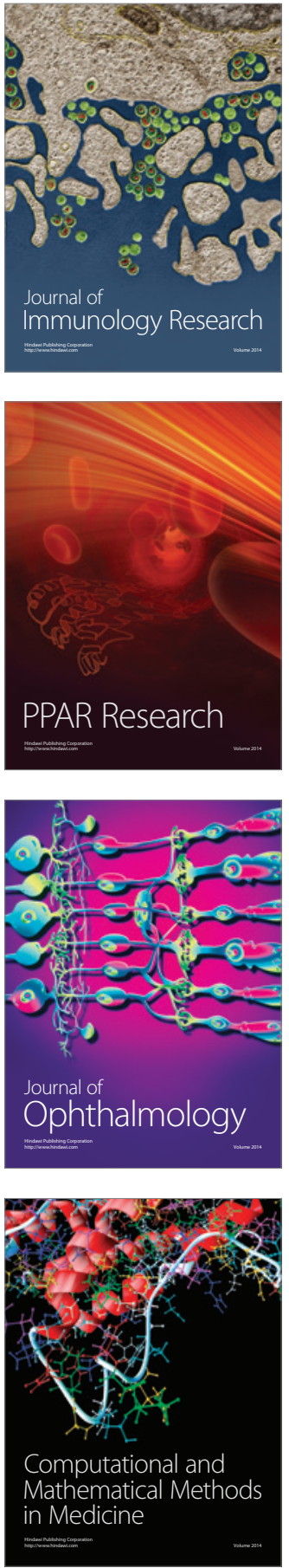

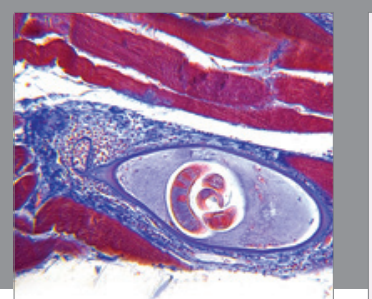

Gastroenterology Research and Practice

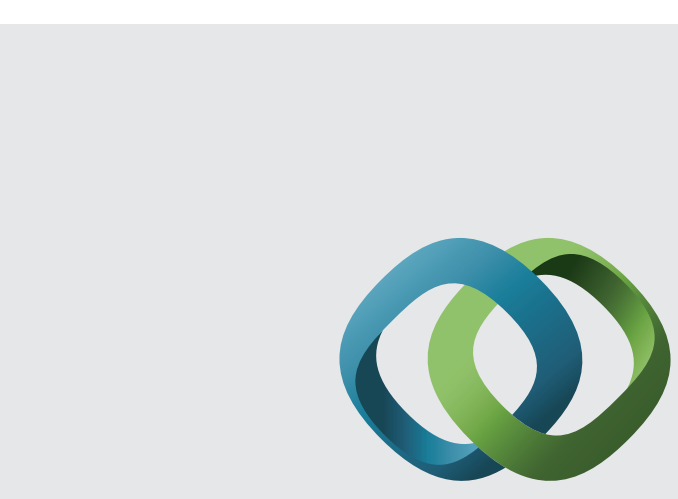

\section{Hindawi}

Submit your manuscripts at

http://www.hindawi.com
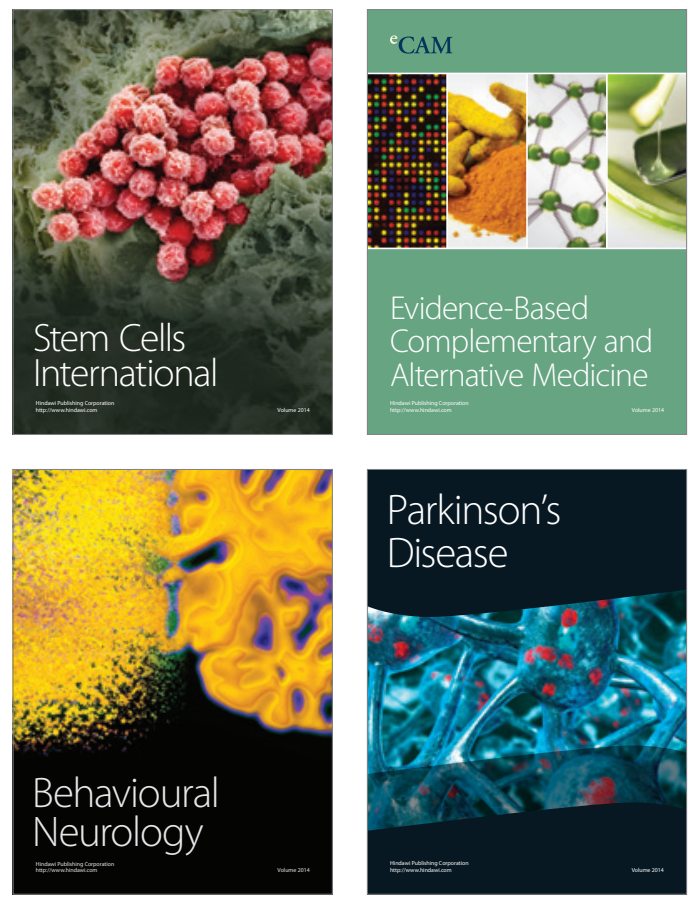
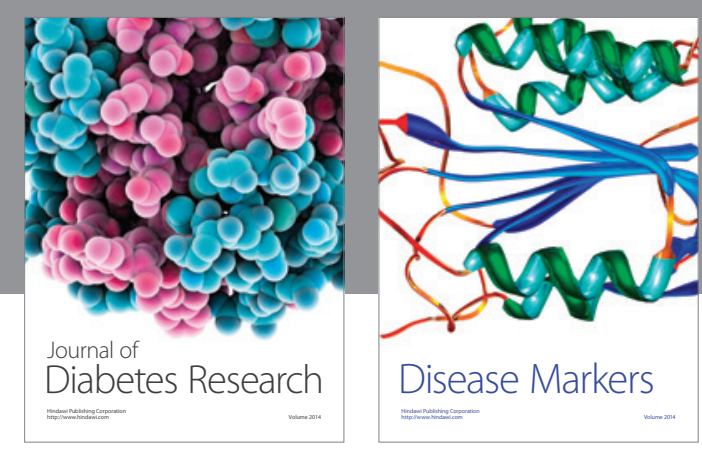

Disease Markers
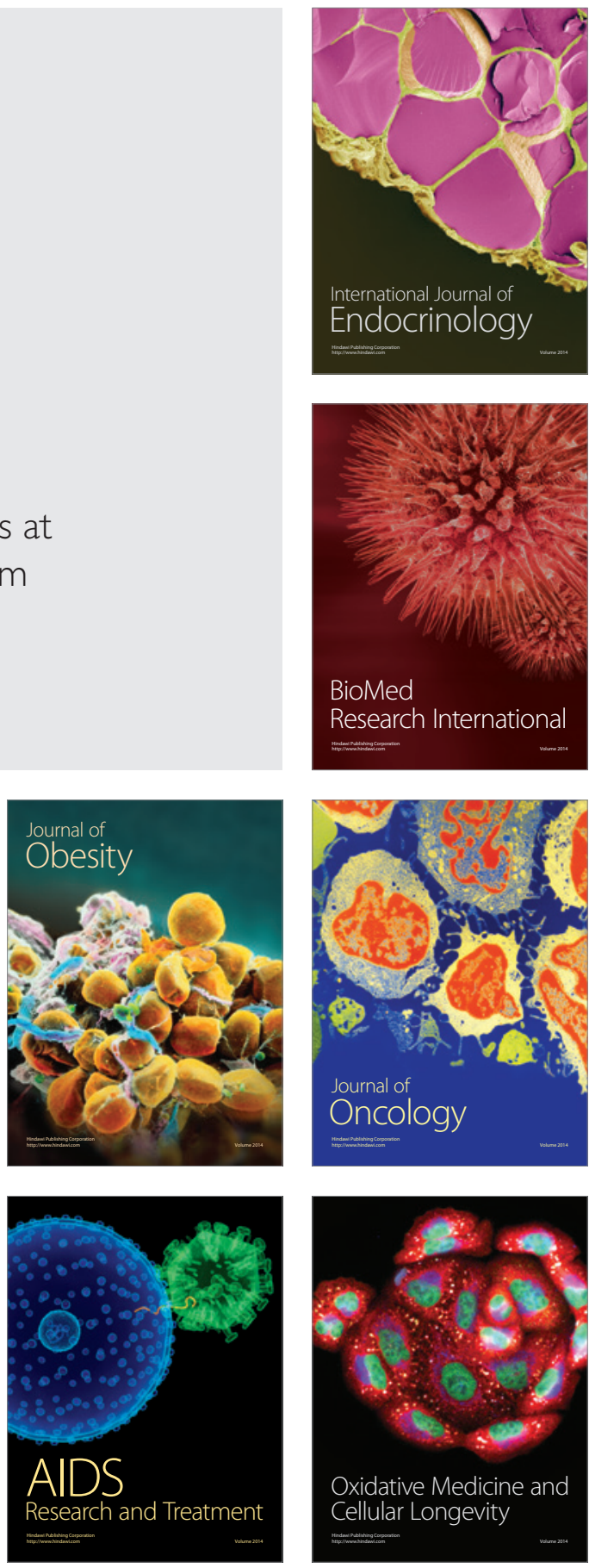